\title{
SUBSÍDIOS PARA ANÁLISE DO DESENVOLVIMENTO RURAL DAS MICRORREGIÕES DO ESTADO DO PARANÁ
}

\author{
Salatiel Turra ${ }^{1}$ \\ Cármem Ozana de Melo2
}

\begin{abstract}
Resumo
Este trabalho tem por objetivo analisar o desenvolvimento rural das microrregiões geográficas do estado do Paraná, pretendendo-se, especificamente, aferir um índice de desenvolvimento, verificando os fatores determinantes desse desenvolvimento e hierarquizando as microrregiões, segundo o nível desenvolvimento. Através da análise fatorial, foi possível verificar que, numa escala de zero a cem, o índice médio de desenvolvimento rural situou-se em 36,17 (trinta e seis com dezessete), resultando num total de dezesseis microrregiões $(41,03 \%)$ acima deste valor e vinte e três microrregiões $(58,97 \%)$ abaixo deste índice. A ordena ção de acordo com o grau de desenvolvimento evidenciou que mais da metade das microrregiões se encontra nos níveis baixo e muito baixo de desenvolvimento rural, sugerindo a necessidade de medidas para minimizar os efeitos gerados pelo processo de modernização agrícola.
\end{abstract}

Palavras-chave: Desenvolvimento regional - Desenvolvimento rural - Modernização agrícola

\section{GRANTS FOR ANALYSIS OF RURAL DEVELOPMENT REGIONS OF STATE OF PARANA}

\begin{abstract}
This paper aims to analyze the development of rural micro geographic Paraná state, intending to specifically measure an index of development, checking the determinants of this development and a hierarchical micro regions, according to the development level. Through factor analysis, we found that, on a scale of zero to one hundred, the average rural development stood at 36.17 (thirty-six to seventeen), resulting in a total of sixteen micro $(41.03 \%)$ above this value and twenty-three micro-regions $(58.97 \%)$
\end{abstract}

\footnotetext{
1 Graduação em Ciências Econômicas (UNIOESTE). Mestrando em Gestão e Desenvolvimento Regional (UNIOESTE). Responsável pelo Departamento de Economia Rural (DERAL) da Secretaria de Estado da Agricultura e do Abastecimento (SEAB). E-mail: salatielturra@hotmail.com

2 Professora do Centro de Ciências Sociais Aplicadas e Coordenadora do Programa de Pós-graduação Stricto Sensu em Gestão e Desenvolvimento Regional da Universidade Estadual do Oeste do Paraná (UNIOESTE). Doutorado em Agronomia (UNESP). E-mail: carozmelo@bol.com.br
} 
below this index. The ordering according to the degree of development showed that more than half of the micro is in the low and very low levels of rural development, suggesting the need for measures to minimize the effects generated by the process of agricultural modernization.

Key-words: Regional development - Rural development - Agricultural modernization

\section{INTRODUÇÃO}

A busca pelo crescimento econômico, entendido como sinônimo de desenvolvimento se deu, especialmente a partir dos anos 1950, com especial atenção à industrialização. Neste contexto, a agricultura teria papel importante a desempenhar, dando suporte ao processo de industrialização, tornando-se absorvedora de produtos advindos do setor industrial, o que passou a configurar o próprio processo de modernização agrícola.

As maiores transformações com relação à modernização da agricultura brasileira se deram principalmente nos anos 1960 e 1970. Segundo Santos (1986), especificamente a partir da década de 1960, o uso de máquinas, adubos e defensivos químicos ganharam importância, gerando aumento da produção e produtividade agrícola.

Nos anos de 1960-70, a agricultura necessitava reestruturar-se de modo que elevasse sua produtividade. Possuía como meta principal produzir de forma que o retorno fosse o maior e o mais rápido possível. Nos anos 1970, também surgem como produto da modernização agrícola os complexos agroindustriais representando a integração técnica entre a indústria e a agricultura.

Assim, de acordo com os parâmetros da chamada "Revolução Verde", associou-se um pacote tecnológico à agricultura, tendo como resultado a mudança da sua base técnica de produção.

Segundo Navarro (2001, p. 84), "a Revolução Verde" materializou-se de fato sob um padrão tecnológico implantado de forma significativa, integrando as famílias rurais a novas formas de racionalidade produtiva, mercantilizando gradualmente a vida social e, em lento processo histórico, quebrando a relativa autonomia setorial".

Em consequência da mecanização agrícola, nas décadas de 1970 e 1980, ocorreu um aumento significativo do êxodo rural. Segundo AGRA (2001), aproximadamente 30 milhões de pequenos produtores foram expulsos de suas terras. A alternativa que restava àquela população rural era vender a força de trabalho nos centros industriais das cidades, aumentando assim, consideravelmente a migração rural/urbano (MARTINE, 1990).

Também no Paraná, o fenômeno teve grande importância. O estado inseriu se no processo, a agricultura se modernizou, o que gerou importantes transformações em sua economia e no meio rural. Pereira (1987) destaca que a estratégia de modernização tecnológica da agricultura brasileira nos anos 1970, causou grandes transformações, especialmente nas regiões ou estados em que a utilização do capital monopolista foi mais acentuada, como o Paraná. Neste sentido, afirma que "a penetração acelerada do capital monopolista na economia e especialmente na agricultura paranaense, dentro do padrão de acumulação adotado, provocou profundas alterações na composição da produção agropecuária e em sua base tècnica" (PEREIRA, 1987, p.169). 
Segundo Moretto; Rodrigues e Parré (2002) as bases da atual estrutura produtiva do Paraná foram iniciadas nos anos 1970, quando ocorreu a modernização da agricultura e a ampliação do parque agroindustrial. Os mesmos autores apontam que esse processo foi caracterizado pela concentração fundiária, introdução de culturas mecanizadas e transformação tecnológica. As mudanças se deram no sentido de uma agricultura ligada essencialmente à monocultura cafeeira e uma indústria pouca dinâmica, para um processo de articulação e reestruturação, que resultou em uma nova forma de inserção e competição da economia do estado.

É interessante destacar que a análise agregada para o estado não permite visualizar de forma clara as desigualdades regionais. Analisando a dinâmica populacional do Paraná, Doretto et al (2003), expõem que a população paranaense encontra-se distribuída espacialmente de forma desigual pelo território. Os autores agrupam em quatro formas distintas esta dinâmica populacional, retratando em uma delas, a condição da grande maioria dos municípios que possuem as menores populações e que estão localizados em regiões rurais. Nestes fica evidenciado que a população, tanto em termos absolutos quanto relativos, representa uma proporção pouco expressiva em relação ao total do estado, sendo que esta mudança foi basicamente provocada pelo esvaziamento populacional ocorrido, principalmente, nas décadas de 1970 e 1980, quando ocorreu o intenso processo de mudança da base técnica da produção agropecuária

Relacionando a questão das desigualdades regionais relativas à distribuição populacional e de renda, o IPARDES (2004) apresenta resultados acerca do número e distribuição das famílias pobres e taxa de pobreza segundo mesorregiões geográficas do Paraná. De acordo com o estudo, em termos relativos, as duas regiões que agregam um percentual considerável de população rural (Sudeste, cerca de $46,4 \%$ da população vive no meio rural e Centro Sul: $39,1 \%$ ), são também as que apresentam maiores percentuais de famílias pobres. Na outra ponta está a região Metropolitana de Curitiba, que possui a menor proporção de população rural (cerca de $9,4 \%$ das pessoas residem na zona rural) e também o menor percentual de famílias pobres.

Neste contexto, importante se faz estudos que abordem o tema, uma vez que se pressupunha que o processo de modernização da agricultura teria como consequência natural o desenvolvimento rural.

Sendo assim, o presente trabalho tem por objetivo aferir o grau de desenvolvimento rural das regiões paranaenses e hierarquizá-las segundo o grau de desenvolvimento. O propósito de construir um Índice de Desenvolvimento Rural (IDR) baseia-se na percepção de que a modernização da agricultura das microrregiões paranaenses, a partir dos anos 1970, constitui fato relevante que gerou impactos no crescimento e no modo de produção da economia agrícola regional.

Com o intuito de focalizar as particularidades regionais, possibilitando verificar desigualdades e potencialidades, este estudo toma como unidade de análise as microrregiões geográficas do estado.

O Estado do Paraná, segundo o censo do IBGE 2010, conta com uma população, em 2010, de 10.444.526 habitantes. De acordo com o IPARDES (2011), possui área de $199.316,694 \mathrm{~km}^{2}$, densidade demográfica de $52,40 \mathrm{hab} / \mathrm{km}^{2}$ num total de 399 municípios, divididos em 10 mesorregiões e 39 microrregiões, sendo estas: Apucarana, Umuarama, Cianorte, Goioerê, Campo Mourão, Astorga, Porecatu, Floraí, Maringá, Paranavaí, Londrina, Faxinal, Ivaiporã, Assaí, Cornélio Procópio, Jacarezinho, Ibaiti, Wenceslau Braz, Telêmaco Borba, Jaguariaíva, Ponta Grossa, Toledo, Cascavel, Foz do Iguaçu, Capanema, Francisco Beltrão, Pato Branco, Pitanga, Guarapuava, Palmas, Prudentópolis, Irati, União da Vitória, São Mateus do Sul, Cerro Azul, Lapa, Curitiba, Paranaguá e Rio Negro. 


\section{METODOLOGIA}

\subsection{Método de Análise}

A proposta deste estudo está baseada em trabalhos que abordaram o tema através da análise estatística multivariada, mais especificamente, a análise fatorial.

A análise fatorial tem como princípio básico a redução do número original de variáveis, por meio da extração de fatores independentes, de tal forma que estes fatores possam explicar, de forma simples e reduzida, as variáveis originais. Em suma, esta técnica permite extrair um número reduzido de fatores, que são combinações lineares das variáveis originais, perdendo o mínimo de informações.

Este método de análise é muito empregado, como aponta Haddad (1989) para juntar regiões ou locais de acordo com a similaridade de seus perfis; e agrupar variáveis para delinear padrões de variações nas características. Estes agrupamentos definem um conjunto de fatores que permitem identificar $o$ estágio de desenvolvimento econômico, social, urbano e outros tipos de desenvolvimento de um determinado local ou região. A análise fatorial pode ser realizada através do método de componentes principais, que faz com que o primeiro fator contenha o maior percentual de explicação da variância total das variáveis da amostra, o segundo fator contenha o segundo maior percentual, e assim por diante (Ferreira Junior et al., 2003).

O método de análise fatorial pode ser expresso na forma matemática através de uma combinação linear entre as variáveis $\left(X_{i}\right)$ e $K$ fatores comuns $(F)$ :

$$
\begin{array}{lllllllll}
X_{i} & A_{i 1} F_{1} & A_{i 2} F_{2} & \ldots & A_{i k} F_{k} & U_{i} & E_{i}
\end{array}
$$

Em que:

$A_{i k}$ - Cargas fatoriais, usadas para combinar linearmente os fatores comuns

$F_{1}, F_{2}, \ldots, F_{k}$ - Fatores comuns

$\mathrm{U}_{\mathrm{i}}$ - Fator único

$E_{i}$ - Fator de erro

As cargas fatoriais indicam a intensidade das relações entre as variáveis normalizadas $X_{i}$ e os fatores. Quanto maior uma carga fatorial, mais associada com o fator se encontra a variável. A variância comum $h_{i}{ }^{2}$, ou comunalidade, representa quanto da variância total de $X_{i}$ é reproduzida pelos fatores comuns, sendo calculada a partir do somatório ao quadrado das cargas fatoriais. A variância única $U_{i}$ é à parte da variância total que não se associa com a variância das outras variáveis. $O$ termo $E_{i}$ representa o erro de observação, de mensuração ou de especificação do modelo.

A medida denominada de Eingevalue ou raiz característica expressa a variância total do modelo explicada por cada fator. De acordo com Ferreira Junior et al (2003), na determinação do número de fatores necessários para representar o conjunto de dados, usualmente consideram-se apenas os fatores cuja raiz característica é maior que a unidade. O seu valor é o somatório dos quadrados das cargas fatoriais de cada variável associadas ao fator específico. O eingevalue dividido pelo número de variáveis $\left(\mathrm{X}_{\mathrm{i}}\right)$ determina a proporção da variância total explicada pelo fator.

Para a interpretação destes fatores é realizada uma rotação ortogonal pelo método varimax, que procura minimizar o número de variáveis fortemente 
relacionadas com cada fator, permitindo, assim, obter fatores mais facilmente interpretáveis.

No modelo de análise fatorial, dois testes são feitos: o Kaiser-Meyer-Olkin Measure of Sampling Adequacy (KMO), que examina o ajuste dos dados, tomando todas as varáveis simultaneamente. Seu valor varia entre zero e um, sendo interpretado como adequado quando apresentar valor acima de 0,50 (BARROSO; ARTES, 2003). O outro teste, que precede a análise fatorial, comvistas à verificação de suas premissas, é o Barlett Test of Sphericity (BTS), que testa a hipótese de que a matriz de correlação é uma matriz identidade.

Através da utilização do software SPSS (versão 11.5), foram obtidos os fatores e selecionados os que apresentaram valores maior que 1. Identificados os fatores, foi feita a estimação do escore fatorial, por meio do método semelhante ao da regressão. O escore para cada observação (microrregião) é resultado da multiplicação do valor (padronizado) das variáveis pelo coeficiente do escore fatorial correspondente, sendo a expressão geral para estimação do j-ésimo fator $F_{\mathrm{j}}$ dada por:

$$
F_{j} \quad W_{j 1} X_{1} \quad W_{j 2} X_{2} \quad W_{j 3} X_{3} \quad \ldots \quad W_{j p} X_{p}
$$

em que os $W_{j i}$ são os coeficientes dos escores fatoriais e $p$ é o número de variáveis.

Os escores fatoriais de cada fator possuem distribuição normal, com média zero e variância unitária e, desse modo, podem ser utilizadas para indicar a posição relativa de cada observação relativamente ao conceito expresso pelo fator. Assim, a partir da matriz dos escores fatoriais, é possível construir um índice para hierarquizar as observações (MONTEIRO; PINHEIRO, 2004).

Através da média aritmética simples dos fatores pertencentes a cada observação (microrregião) foi obtido o Índice Bruto de Desenvolvimento Rural (IB) das microrregiões (eq. 3):

$$
\text { IB } \frac{i_{1}^{n}\left(F_{i}\right)}{n}
$$

Sendo:

IB = índice bruto (média aritmética simples dos escores fatoriais)

$\mathrm{F}_{\mathrm{i}}=$ escores fatoriais

$\mathrm{n}=$ número de fatores (escores fatoriais)

A partir daí, por meio da interpolação, considerando-se como o maior valor igual a 100 e o menor igual a zero, obteve-se o Índice de Desenvolvimento Rural (IDR) para cada microrregião do Estado. O quadro I, apresenta as categorias adotadas para classificação de desenvolvimento rural, considerando o desvio padrão em torno da média.

\begin{tabular}{|c|c|c|}
\hline Categoria & Sigla & Desvio Padrão $(\sigma)$ \\
\hline Alto & $\mathrm{A}$ & $A \geq(M+1 \sigma)$ \\
\hline Médáç & $M$ & Mèdia $\leq \mathrm{M}<\mathrm{A}$ \\
\hline Baáxç & $\mathrm{B}$ & $\mathrm{MB} \leq \mathrm{B}<$ Mèdia \\
\hline Muátç Baáxç & MB & MB $\leq($ Mèdia- $1 \sigma)$ \\
\hline
\end{tabular}

Tabela 1- Categorias de Desenvolvimento Rural

Fonte: Elaborada pelos autores. 


\subsection{Variáveis e fontes dos dados}

Foram selecionadas neste estudo 14 variáveis como indicadores de desenvolvimento rural das microrregiões do estado: $\mathbf{X}_{1}$ : densidade demográfica rural; $\mathbf{X}_{2}$ : proporção de população rural; $\mathbf{X}_{3}$ : área explorada; $\mathbf{X}_{4}$ : População masculina total no meio rural em relação à população feminina total no meio rural; $\mathbf{X}_{5}$ : Número de domicílios particulares permanentes rurais com instalação sanitária; $\mathbf{X}_{6}$ : Consumo de energia elétrica rural; $\mathbf{X}_{\mathbf{7}}$ : Número de consumidores de energia elétrica rural; $\mathbf{X}_{\mathbf{8}}$ : Número de estabelecimentos agropecuários que obtiveram financiamentos de custeio, investimento e comercialização e manutenção de estabelecimento; $\mathbf{X}_{\mathbf{9}}$ : Número de tratores existentes nos estabelecimentos agropecuários; $\mathbf{X}_{10}$ : Valor das despesas realizadas com agrotóxicos por estabelecimentos no período de 01/01 a 31/12/10; $\mathbf{X}_{11}$ : Valor das despesas realizadas com adubos pelo estabelecimento no período de 01/01 a 31/12/10; $\mathbf{X}_{12}$ : Valor das despesas realizadas com combustível pelo estabelecimento no período de 01/01 a 31/12/10; $\mathbf{X}_{13}$ : Valor Bruto da Produção Agropecuária (VBP); $\mathbf{X}_{14}$ : Número de alunos matriculados nos ensinos pré-escolares, fundamental e médio - zona rural.

Os dados utilizados para a execução da pesquisa são secundários e obtidos através de estudos e do banco de dados do Instituto Paranaense de Desenvolvimento Econômico e Social - IPARDES, do Instituto Brasileiro de Geografia e Estatística IBGE e do Departamento de Economia Rural - DERAL da Secretaria de Estado da Agricultura e do abastecimento do Paraná - SEAB, disponíveis nos site das instituições (http://www.seab.pr.gov.br).

\section{RESULTADOS E DISCUSSÕES}

A análise aplicada ao modelo possibilitou a extração de três fatores com raiz característica maior que a unidade e que sintetizam as informações contidas nas 14 variáveis originais. Após rotação, conforme tabela 1, percebe-se que os quatro fatores selecionados explicam, em conjunto, $77,33 \%$ da variância total das variáveis selecionadas. O resultado desta variância é justificado por Hair et al., (2009), apud (STEGE, 2011), pois segundo o autor, obter uma variância acumulada de $60 \%$ é satisfatório nas ciências sociais.

Tabela 2 -Raiz característica, percentual explicado por cada fator e variância acumulada.

\begin{tabular}{cccc}
\hline Fator & Raiz característica & $\begin{array}{c}\text { Variância } \\
\text { explicada pelo } \\
\text { fator (\%) }\end{array}$ & $\begin{array}{c}\text { Variância } \\
\text { acumulada (\%) }\end{array}$ \\
\hline F1 & 5,13 & 36,643 & 36,643 \\
F2 & 4,098 & 29,269 & 65,911 \\
F3 & 1,599 & 11,42 & 77,332 \\
\hline
\end{tabular}

Fonte: Resultados da pesquisa. 
O teste de Bartlett ${ }^{1}$ mostrou-se significativo, rejeitando a hipótese nula de que a matriz de correlação é uma matriz identidade. O teste de $\mathrm{KMO}$, para análise da adequabilidade da amostra, apresentou valor de 0,772 , indicando que a amostra é passível de ser analisada pelas técnicas da análise fatorial.

A tabela 2 apresenta as cargas fatoriais e as comunalidades para os fatores considerados. Para melhor interpretação, foram consideradas apenas as cargas fatoriais com valores superiores 0,50 (destacadas em negrito), buscando evidenciar os indicadores mais fortemente associados a determinado fator. Os valores encontrados para as comunalidades revelam que todas as variáveis têm sua variabilidade captada e representada pelos três fatores.

Tabela 3 - Cargas Fatoriais e Comunalidades

\begin{tabular}{ccccc}
\hline & \multicolumn{3}{c}{ Cargas fatoriais } & \multirow{2}{*}{ Comunalidades } \\
\cline { 2 - 4 } Indicadores & $\mathbf{F 1}$ & $\mathbf{F 2}$ & $\mathbf{F 3}$ & \\
\hline $\mathbf{X}_{\mathbf{1}}$ & $\mathbf{0 , 7 0 7}$ & $-0,378$ & $-0,243$ & 0,702 \\
$\mathbf{X}_{\mathbf{2}}$ & 0,122 & $-0,087$ & $\mathbf{- 0 , 9 2 2}$ & 0,873 \\
$\mathbf{X}_{\mathbf{3}}$ & 0,298 & $\mathbf{0 , 6 9 1}$ & 0,081 & 0,573 \\
$\mathbf{X}_{\mathbf{4}}$ & $\mathbf{- 0 , 5 5 1}$ & $-0,254$ & $-0,114$ & 0,381 \\
$\mathbf{X}_{\mathbf{5}}$ & $\mathbf{0 , 8 9 3}$ & 0,186 & 0,083 & 0,840 \\
$\mathbf{X}_{\mathbf{6}}$ & $\mathbf{0 , 6 7 0}$ & 0,483 & 0,483 & 0,915 \\
$\mathbf{X}_{\mathbf{7}}$ & $\mathbf{0 , 8 8 0}$ & 0,392 & 0,093 & 0,937 \\
$\mathbf{X}_{\mathbf{8}}$ & $\mathbf{0 , 7 2 4}$ & 0,512 & $-0,101$ & 0,797 \\
$\mathbf{X}_{\mathbf{9}}$ & $\mathbf{0 , 5 7 0}$ & $\mathbf{0 , 6 5 7}$ & 0,366 & 0,890 \\
$\mathbf{X}_{\mathbf{1 0}}$ & $-0,022$ & $\mathbf{0 , 8 4 2}$ & 0,029 & 0,710 \\
$\mathbf{X}_{\mathbf{1 1}}$ & $\mathbf{0 , 0 4 5}$ & $\mathbf{0 , 7 9 5}$ & 0,052 & 0,637 \\
$\mathbf{X}_{\mathbf{1 2}}$ & $\mathbf{0 , 4 5 2}$ & $\mathbf{0 , 7 9 8}$ & 0,311 & 0,938 \\
$\mathbf{X}_{\mathbf{1 3}}$ & $\mathbf{0 , 6 7 2}$ & $\mathbf{0 , 5 5 7}$ & 0,336 & 0,874 \\
$\mathbf{X}_{\mathbf{1 4}}$ & $\mathbf{0 , 8 3 2}$ & $-0,031$ & $-0,254$ & 0,758 \\
\hline
\end{tabular}

Fonte: Resultados da pesquisa.

O Fator 1 está positivo e fortemente relacionado com os indicadores $\mathbf{X}_{1}$ (expressa a densidade demográfica rural), a variável, $\mathbf{X}_{5}$ (número de domicílios particulares permanentes rurais com instalação sanitária); $\mathbf{X}_{6}$ e $\mathbf{X}_{7}$ (que denotam a utilização de energia elétrica no meio rural); $X_{8}$ (número de estabelecimentos agropecuários que obtiveram algum tipo de financiamento); $\mathbf{X}_{13}$ (refere-se ao valor bruto da produção (VBP) agropecuária) e $\mathbf{X}_{14}$ (que refere-se ao número de alunos matriculados). O Fator 1 possui a maior variância explicada pelo fator, correspondendo com $36,643 \%$ do total da variância acumulada, expressando assim a importância das variáveis relacionadas para o desenvolvimento rural. Este fator está

\footnotetext{
${ }^{1}$ Teste BTS: 612,622 (nível de significância: 0,000).
} 
ligado à densidade demográfica rural, ao bem-estar, a renda agrícola e a educação das microrregiões.

As variáveis relacionadas a esse fator e que se mostraram com maior peso para o fenômeno em estudo, representam o alicerce, a estrutura para 0 desenvolvimento das atividades agrícolas e rurais. $O$ indicador densidade demográfica, de modo geral, deve favorecer o desenvolvimento, uma vez que, em tese, quanto maior a densidade demográfica, menor o isolamento dessas áreas e maiores as oportunidades de estabelecimento de redes sociais e, portanto, maior a capacidade de retenção de pessoas neste espaço. Neste mesmo sentido, está o indicador de utilização de energia elétrica e a disponibilidade de financiamento para atividade agrícola, que fornecem subsídios à produção e, com isso, manutenção da atividade rural.

O fator 2 está relacionado com a área explorada $\left(\mathbf{X}_{3}\right) ; \mathbf{X}_{\mathbf{9}}$ (que expressa o número de tratores existentes nos estabelecimentos agropecuários); $\mathbf{X}_{10}$ (valor das despesas realizadas com agrotóxicos por estabelecimentos no período de 01/01 a 31/12- $R \$$ ); e os indicadores $\mathbf{X}_{11}$ e $\mathbf{X}_{12}$ (que demonstram o valor das despesas com adubos e combustíveis). O Fator 2 possui a segunda maior variância, correspondendo a $29,269 \%$ do total da variância acumulada. A relação direta do fator com as variáveis indicativas de modernização agrícola denota a importância da inovação tecnológica para o grau de desenvolvimento rural das microrregiões do estado.

No fator 3 , encontra-se negativo e fortemente relacionado apenas à variável $\mathbf{X}_{2}$ (proporção de população rural). Tal correlação alta e negativa pode estar associada ao fato de que, o contingente masculino tradicionalmente é maior proporção no meio rural e, com o processo de modernização, a mão-de-obra tem sido substituída pelo uso de máquinas, haja vista a relação alta e positiva com os indicadores apresentados no caso do Fator 2. Pode-se ainda chamar a atenção, neste aspecto, da relação negativa da variável $\mathbf{X}_{4}$ (que expressa a proporção de população rural) com o Fator 1, sugerindo o mesmo tipo de análise: no processo implantado e implementado da modernização agrícola, o alcance dos resultados de ganhos de produção e produtividade geraram maior uso de máquinas, equipamentos e insumos, em detrimento ao uso de mão de obra, o que pode ter se refletido no contingente de pessoas que vivem no meio rural, especialmente as do gênero masculino.

Uma vez verificadas as cargas fatoriais, o passo seguinte é observar os escores fatoriais, ou seja, o valor do fator para cada microrregião. A análise do fator deve ser feita levando em conta que seus escores originais, quando considerados todas as microrregiões em conjunto, são variáveis com média zero e desvio padrão igual a 1. Portanto, pode-se interpretar que os escores com valores próximos de zero indicam nível de desenvolvimento médio e, quanto maior em relação a zero for o fator, mais avançado será a região, no que se refere ao significado do fator em consideração.

$\mathrm{Na}$ escala de zero a 100, o índice de desenvolvimento rural (IDR) médio situou-se em 36,17; o desvio-padrão foi de 18,11 gerando os seguintes limites inferiores e superiores para a determinação da categoria do grau de desenvolvimento, conforme tabela 4. 
Tabela 4 - Intervalos do IDR e graus de desenvolvimento rural

\begin{tabular}{ccc}
\hline Categoria & Limite Inferior & Limite Superior \\
\hline A & 54,29 & 100,00 \\
M & 36,17 & 54,28 \\
B & 18,06 & 36,16 \\
MB & 0,00 & 18,05
\end{tabular}

Fonte: Resultados da pesquisa.

A tabela 5 apresenta os resultados para as microrregiões do estado do Paraná. Verifica-se que cinco microrregiões se concentram no maior Grau de Desenvolvimento (alto, A), totalizando $12,82 \%$ do total das microrregiões. Já as que tiveram categoria de médio desenvolvimento rural foram da ordem de $28,21 \%$. Assim, a maioria se situou na categoria de baixo $(46,15 \%)$ e muito baixo $(12,82 \%)$ grau de desenvolvimento rural. Ainda na tabela IV, é possível observar os valores dos Fatores (F1, F2 e F3), o Índice Bruto, o Índice de Desenvolvimento Rural - IDR, o Grau de Desenvolvimento - GD e o Ranking da microrregião no Estado.

Por meio dos escores fatoriais de cada microrregião, é possível verificar os elementos que mais contribuíram para o seu desenvolvimento rural. Observa-se que nas duas regiões com os maiores IDRs e, portanto, com grau de desenvolvimento rural alto (A), todos os fatores apresentaram-se positivos, de modo que as variáveis relacionadas e esses fatores mostram-se importantes para o resultado dessas regiões. É interessante comentar que Toledo e Cascavel são microrregiões consideradas importantes produtoras de soja, cultura que teve destaque no processo de modernização agrícola, além de se destacar também a produção avícola e suinícola (atividades estas que são fortes demandantes de soja e milho), o que pode ter se refletido no resultado do fator $\mathrm{F} 2$, relacionado ao uso de máquinas e insumos „modernos". Ademais, para as outras três microrregiões que tambèm tiveram grau de desenvolvimento alto, pelo menos dois dos três fatores mostraram-se positivos.

Tabela 5 - Fatores, índice bruto, índice de desenvolvimento rural, grau de desenvolvimento e ranking das Microrregiões do Paraná.

\begin{tabular}{lllllllc}
\hline Microrregiões & Fator $\mathbf{1}$ & Fator 2 & Fator 3 & Índice Bruto & IDR & GD & Ranking \\
\hline Toledo & 1,91234 & 2,6776 & 1,5128 & 2,0342933 & 100 & $\mathrm{~A}$ & 1 \\
Cascavel & 1,05616 & 1,0613 & 0,9764 & 1,0313066 & 68,5 & $\mathrm{~A}$ & 2 \\
Curitiba & 3,14204 & $-1,885$ & 1,0456 & 0,7675166 & 60,2 & $\mathrm{~A}$ & 3 \\
Francisco Beltrão & 2,51392 & $-0,108$ & $-0,2995$ & 0,70208 & 58,2 & $\mathrm{~A}$ & 4 \\
Guarapuava & 1,55016 & 1,2054 & $-0,9246$ & 0,6103266 & 55,3 & $\mathrm{~A}$ & 5 \\
Ponta Grossa & 0,20749 & 0,1281 & 1,3340 & 0,5565533 & 53,6 & $\mathrm{M}$ & 6 \\
Paranavaí & $-0,1837$ & 0,5485 & 0,9789 & 0,44789 & 50,2 & $\mathrm{M}$ & 7 \\
Foz do Iguaçú & 0,26696 & $-0,043$ & 1,0962 & 0,4398666 & 49,9 & $\mathrm{M}$ & 8 \\
Campo Mourão & $-0,9177$ & 2,8644 & $-0,6924$ & 0,41806 & 49,2 & $\mathrm{M}$ & 9 \\
Umuarama & 0,28686 & 0,3816 & 0,5178 & 0,3954633 & 48,5 & $\mathrm{M}$ & 10
\end{tabular}




$\begin{array}{llllllll}\text { Londrina } & -0,4862 & 0,3667 & 0,9749 & 0,2851433 & 45,1 & \mathrm{M} & 11 \\ \text { Pato Branco } & 0,68463 & -0,213 & 0,3455 & 0,2722266 & 44,7 & \mathrm{M} & 12 \\ \text { Astorga } & -0,4633 & 0,0992 & 1,0940 & 0,2432866 & 43,8 & \mathrm{M} & 13 \\ \text { Goioerê } & -0,9902 & 2,4265 & -0,7842 & 0,2173833 & 43,0 & \mathrm{M} & 14 \\ \text { Cornélio Procópio } & -0,3311 & 0,1890 & 0,6693 & 0,1757566 & 41,6 & \mathrm{M} & 15 \\ \text { Apucarana } & -0,6143 & 0,0131 & 0,7271 & 0,04199 & 37,4 & \mathrm{M} & 16 \\ \text { Cianorte } & -0,7461 & -0,066 & 0,6575 & -0,0516633 & 34,5 & \mathrm{~B} & 17 \\ \text { Ivaiporã } & 0,57978 & 0,2736 & -1,0419 & -0,0628566 & 34,2 & \mathrm{~B} & 18 \\ \text { Telêmaco Borba } & -0,5427 & 0,9538 & -0,7474 & -0,1120966 & 32,6 & \mathrm{~B} & 19 \\ \text { Maringá } & -0,4812 & -1,011 & 1,1535 & -0,11268 & 32,6 & \mathrm{~B} & 20 \\ \text { Jaguariaíva } & -0,6982 & -0,292 & 0,4965 & -0,1648666 & 31,0 & \mathrm{~B} & 21 \\ \text { Jacarezinho } & -0,5321 & -0,716 & 0,6914 & -0,1858033 & 30,3 & \mathrm{~B} & 22 \\ \text { Porecatu } & -0,9775 & -0,380 & 0,6590 & -0,2329466 & 28,8 & \mathrm{~B} & 23 \\ \text { Capanema } & 0,91283 & -0,820 & -0,8453 & -0,2509 & 28,3 & \mathrm{~B} & 24 \\ \text { Prudentópolis } & 0,9624 & 0,1093 & -1,8711 & -0,26645 & 27,8 & \mathrm{~B} & 25 \\ \text { Palmas } & -0,48646 & -0,0681 & -0,2447 & -0,26646 & 27,82 & \mathrm{~B} & 26 \\ \text { União da vitória } & -0,19205 & -0,4644 & -0,1669 & -0,27447666 & 27,57 & \mathrm{~B} & 27 \\ \text { Assaí } & -0,68911 & -0,4981 & 0,2968 & -0,29680666 & 26,87 & \mathrm{~B} & 28 \\ \text { Wenceslau Braz } & -0,23948 & -0,6776 & -0,0485 & -0,32189333 & 26,08 & \mathrm{~B} & 29 \\ \text { Floraí } & -1,34914 & -0,3902 & 0,6338 & -0,3687433 & 24,61 & \mathrm{~B} & 30 \\ \text { Irati } & -0,11082 & -0,5374 & -0,6989 & -0,44908 & 22,09 & \mathrm{~B} & 31 \\ \text { Paranaguá } & -0,94502 & -1,1890 & 0,6632 & -0,49028 & 20,8 & \mathrm{~B} & 32 \\ \text { Faxinal } & -0,96558 & -0,4703 & -0,1413 & -0,52575 & 19,68 & \mathrm{~B} & 33 \\ \text { Pitanga } & -0,10568 & 0,4293 & -1,9499 & -0,54208 & 19,17 & \mathrm{~B} & 34 \\ \text { Ibaiti } & -0,83107 & -0,7162 & -0,2318 & -0,5930333 & 17,57 & \mathrm{MB} & 35 \\ \text { Lapa } & -0,36318 & -0,8174 & -0,6107 & -0,5971333 & 17,44 & \mathrm{MB} & 36 \\ \text { Rio Negro } & 0,76543 & -1,1667 & -1,4550 & -0,6188 & 16,76 & \mathrm{MB} & 37 \\ \text { São Mateus do Sul } & 0,02093 & -0,6923 & -1,4323 & -0,7012433 & 14,18 & \mathrm{MB} & 38 \\ \text { Cerro Azul } & -0,61931 & -0,5021 & -2,3378 & -1,15311 & 0,00 & \mathrm{MB} & 39\end{array}$

Fonte: Resultados da pesquisa.

No outro extremo, pode-se observar que as microrregiões com grau de desenvolvimento rural muito baixo (MB), tiveram praticamente todos os fatores negativos, espelhando assim os aspectos que necessitam de mais atenção, ao se considerar as variáveis com maior correlação com tais fatores.

Neste aspecto, cabe chamar a atenção para o fato de que já a partir de microrregiões com grau de desenvolvimento rural (M), é possível observar microrregiões com o fator F1 negativo: das 34 (trinta e quatro) microrregiões com grau M. B e MB, 26 (vinte e seis) apresentaram tal característica. Lembrando que no Fator F1 varáveis relacionadas à população rural e sua qualidade de vida (densidade demográfica rural, número de domicílios particulares permanentes rurais com 
instalação sanitária, utilização de energia elétrica no meio rural, número de estabelecimentos agropecuários que obtiveram algum tipo de financiamento, valor bruto da produção agropecuária e número de alunos matriculados), importante se faz atentar para o fato de que aspectos ligados a pessoas que vivem no meio rural necessitam de maior atenção na busca do alcance do desenvolvimento.

É possível observar, através da Figura 1, a distribuição espacial do desenvolvimento rural das microrregiões do estado, de acordo com o IDR e sua classificação em GD.

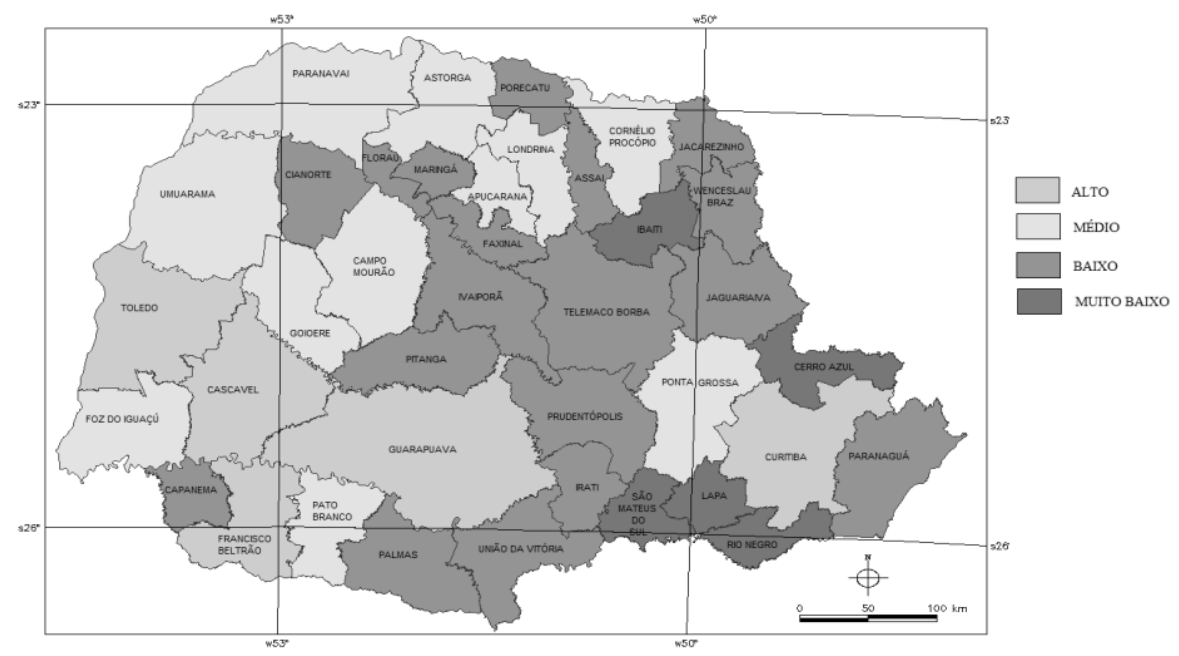

\section{Figura 1 - Distribuição espacial do Índice de Desenvolvimento Rural das Microrregiões Geográficas do Estado do Paraná, 2011.}

Fonte: Resultados da pesquisa

Pelo mapa é possível observar certa contiguidade das microrregiões, em relação ao grau de desenvolvimento rural. As regiões com GD alto, por exemplo, constituem uma "faixa" situada mais para o oeste/sudoeste do estado. Neste caso, trata-se de regiões que absorveram o processo de modernização, apresentando resultados expressivos de sua agropecuária. As microrregiões de Cascavel, Toledo e Francisco Beltrão são importantes produtoras de soja, milho, aves e suínos. Produtos estes (especialmente milho e soja) ícones do processo de modernização agrícola. Vale lembrar que as variáveis VPB, financiamentos, energia elétrica e uso de "insumos modernos" tiveram peso importante na determinação dos fatores 1 e 2, componentes principais do IDR.

Tais questões deixam transparecer as desigualdades regionais do estado, em termos de desenvolvimento rural, uma vez que é possível visualizar resultados de regiões em que as variáveis de maior peso não contribuíram para o desenvolvimento acima da média, expressando assim impactos negativos para tais localidades.

Ademais, confirma-se à hipótese de que o processo de modernização da agricultura no estado caracterizou-se como um fator importante de desenvolvimento, pois a variável X2 (proporção de população rural) e X4 (proporção masculina no meio rural com relação à proporção feminina no meio rural) possuem relação negativa, e em contrapartida, as variáveis que compõem o F2 (inovação tecnológica), possuem 
relação forte e positivamente com os indicadores com cargas fatoriais superiores a 0,50 , substituindo assim, a mão-de-obra rural.

\section{CONSIDERAÇÕES FINAIS}

A busca pelo desenvolvimento constitui uma tarefa continua que demanda constantemente estudos e informações acerca do fenômeno. Neste sentido, focar determinado segmento torna-se importante, à medida que desperta a atenção sobre um aspecto ou contingente de pessoas que vivem em determinada realidade ou mesmo que absorveu impactos da opção feita no Brasil pela industrialização atrelada ao processo de modernização agrícola.

Buscando esta visualização, este trabalho procurou abordar a questão, considerando variáveis relacionadas ao desenvolvimento rural, aferindo assim uma medida sintética para as microrregiões geográficas do estado do Paraná.

Os resultados permitiram concluir que mais da metade $(58,97 \%)$ das microrregiões estão abaixo da média, o que deixa transparecer a necessidade de maior atenção para as regiões que apresentaram tal resultado.

A análise dos escores fatoriais de cada região pode apontar para as particularidades de cada uma, ou seja, os aspectos que em cada uma merece mais atenção, no sentido de melhorar a sua condição e desenvolvimento. Neste sentido, verifica-se que as variáveis que tiveram mais peso nos resultados dos fatores, acarretaram resultados que contribuíram para que a maioria das microrregiões se situasse abaixo da média.

A classificação de cada microrregião representa sua posição relativa com as demais microrregiões analisadas. A microrregião de Cerro Azul, por exemplo, apresentou o grau de desenvolvimento rural muito baixo, resultando em um IDR igual a 0,00 (zero), porém não significa estar em uma situação péssima, mas sim, quando analisada em relação ao conjunto das microrregiões paranaenses e das variáveis observadas, apresenta-se em uma situação mais precária de IDR.

Cabe considerar a limitação deste estudo que, ao aferir um indicador de desenvolvimento, é limitado nas variáveis inseridas no modelo, de tal modo que, entendendo-se o fenômeno complexo e multissetorial, outros aspectos não abordados poderiam ser considerados relevantes em outro tipo de análise. No entanto, mesmo reconhecendo tal limitação, a partir da mensuração do grau de desenvolvimento de uma microrregião torna-se possível a ação de medidas e de estratégias que estimulem a melhorar o IDR daquela região.

Sendo assim, mesmo não sendo uma medida ideal, pode contribuir para subsidiar estudos que abordem o tema. Neste sentido, os resultados deste estudo não cessam a necessidade de aprofundamento do assunto.

\section{REFERÊNCIAS BIBLIOGRÁFICAS}

AGRA, N. G. et al.; Agricultura brasileira: situação atual e perspectivas de desenvolvimento. UFPB, 2001.

BARROSO, L.P.; ARTES, R. Análise multivariada. $48^{a}$ Reunião Anual da Região Brasileira da Sociedade Internacional de Biometria e $10^{\circ}$ Simpósio de Estatística Aplicada à Experimentação Agronômica. Lavras, 2003. 
DORETTO, M. et al. Mapeamento da pobreza no Paraná: uma situação segundo municípios e Associações de Municípios do Paraná, ano 2000. In: Congresso da Sociedade Brasileira de Economia, Administração e Sociologia Rural. Anais... Juiz de Fora, 2003.

FERREIRA JUNIOR, S. et al., A modernização agropecuária nas microrregiões do estado de Minas Gerais. Congresso da SOBER. SOBER. Juiz de Fora, 2003.

HADDAD, P.R. et al. Economia regional. Fortaleza, BNB, 1989.

HAIR, J. F.; ANDERSON, R. E.; TATHAM, R. L.; BLACK, W. C. Multivariate data analysis. 7 ed. New Jersey: Prentice Hall, 2009.

INSTITUTO PARANANENSE DE DESENVOLVIMENTO ECONÔMICO E SOCIAL IPARDES. Leituras Regionais: Mesorregiões geográficas do Paraná. Curitiba, 2004.

INSTITUTO PARANAENSE DE DESENVOLVIMENTO ECONÔMICO E SOCIAL.. Disponível em: <http://www.ipardes.gov.br/pdf/mapas/base_fisica/microrregioes_geograficas_base_2 010.pdf> Acesso em: 10 setembro 2011

MARTINE, G. Fases e faces da modernização agrícola brasileira. Planejamento e Políticas Públicas, v.1, n.3, p.3-44, jun. 1990.

MORETTO, A C.; RODRIGUES, R.L. \& PARRÉ, J.L. Tendências do agronegócio no Paraná: 1980 a 1995. In: Agronegócio paranaense - potencialidades e desafios. Cascavel, Edunioeste, 2002. p.33-55.

MONTEIRO, V.P.; PINHEIRO, J.C. Critério para implantação de tecnologias de suprimentos de água potável em municípios cearenses afetados pelo alto teor de sal. Revista de Economia e Sociologia Rural. Rio de Janeiro, vol. 42, n. 02, p. 365387, abr/jun 2004.

NAVARRO, Z. Desenvolvimento rural no Brasil: os limites do passado e os caminhos do futuro. Estud. av. [online]. 2001, vol.15, n.43, pp. 83-100. ISSN 01034014.

PEREIRA, L.B. O Estado e as transformações recentes da agricultura paranaense. 1987. Tese (Doutorado em Economia) - Programa de Pós-Graduação em Economia, Universidade Federal de Pernambuco.

SANTOS, R. F., Análise crítica da interpretação neoclássica do processo de modernização da agricultura brasileira. In: SANTOS, R.F. dos. Presença de vieses de mudança técnica da agricultura brasileira. São Paulo: USP/IPE, p.39-78, 1986. 
STEGE, A. L., Desenvolvimento rural nas microrregiões do Brasil: Um estudo multidimensional. 2011. 137f. Dissertação (Mestrado em Ciências Econômicas) Programa de Pós-Graduação em Ciências Econômicas, Universidade Estadual de Maringá. 